\title{
Optimasi Setting Posisi Screen dan Blower terhadap Kapasitas serta Granulasi pada Proses Grinding di PT. Malindofeedmill, Tbk Grobogan
}

\author{
Dimas Ardiansyah Halim ${ }^{1}$, Mukhlis Ibrahim ${ }^{2}$, Muhammad Syahrul Sidiq ${ }^{3}$, Kautzar Rizki \\ Diptaseptian $^{4}$ \\ ${ }^{1,2,3,4}$ Program Studi Teknik Mesin, Akademi Teknik Wacana Manunggal Semarang \\ Email: ${ }^{1}$ dimasardiansyah@atwm.ac.id, ${ }^{2}$ mukhlisibrahim83@gmail.com, \\ ${ }^{3}$ Syahrulsidiq388@gmail.com, ${ }^{4}$ rizki. kautzar@gmail.
}

\begin{abstract}
ABSTRAK
Usaha peningkatan kapasitas dengan tetap menjaga granulasi hasil proses grinding dilakukan untuk memaksimalkan penggunaan mesin hammer mill yang merupakan mesin pengonsumsi energi listrik terbesar kedua pada suatu plant. Metode yang dapat dilakukan untuk mencapai hal tersebut yaitu dengan setting posisi screen dan setting bukaan blower yang tepat. Spesifikasi screen yang sesuai standar akan memaksimalkan kapasitas proses grinding dan menghasilkan granulasi yang optimum. Agar mendapatkan kapasitas proses grinding yang maksimal DFCO dapat disetting maksimum tetapi akan berefek pada arus motor selama proses grinding, arus rata-rata akan cenderung tinggi.

Penelitian yang dilakukan bertujuan untuk mengetahui pengaruh variasi setting posisi screen dan blower terhadap kapasitas dan granulasi bahan baku hasil proses grinding. Penggunaan screen diameter 2,5 $\mathrm{mm}$ dan $3 \mathrm{~mm}$, serta setting posisi screen 2,5 $\mathrm{mm}$ dibagian atas dan $3 \mathrm{~mm}$ dibagian bawah menghasilkan kapasitas dan granulasi yang lebih baik dibandingkan penggunaan screen hanya diameter $3 \mathrm{~mm}$. Semakin besar bukaan blower dan DFCO semakin besar kapasitas proses grinding, tetapi semakin besar pula arus motor. Semakin besar bukaan blower semakin besar pula penurunan kadar air bahan baku hasil grinding.
\end{abstract}

Kata kunci: Kapasitas, Hammermill, Grinding, Screen, Granulasi, Blower

\section{ABSTRACT}

The efforts to increase capacity while maintaining the granulation of the grinding process are carried out to maximize the use of the hammer mill machine, which is the second largest electric energy consumption in a plant. The method that can be done to achieve this is by setting the screen position and setting the right blower opening. Standard screen specifications will maximize the capacity of the grinding process and produce optimum granulation. In order to get the maximum grinding capacity, DFCO can be set at the maximum but will have an effect on the motor current during the grinding process, the average current will tend to be high.

The aim of this research was to determine the effect of variations in the screen's and blower's position settings on the capacity and granulation of raw materials from the grinding process. The usage of $2.5 \mathrm{~mm}$ and $3 \mathrm{~mm}$ diameters screens, as well as adjusting the screen position of $2.5 \mathrm{~mm}$ at the top and $3 \mathrm{~mm}$ at the bottom, resulted in better capacity and granulation than using a screen with only $3 \mathrm{~mm}$ diameter. The larger the blower and DFCO openings, the greater the grinding capacity, but also increased the motor current. The larger the blower opening, the greater the decrease in the water content of grinding raw materials.

Keywords: Capacity, Hammermill, Grinding, Screen, Granulation, Blower 


\section{Pendahuluan}

Rangkaian proses produksi pakan meliputi pemecahan raw material kasar atau grinding, pencampuran beberapa jenis raw material atau mixing, pemadatan pakan atau pelleting, dan pengemasan pakan atau packing. Proses grinding merupakan suatu proses pengurangan ukuran partikel material/bahan baku dari bentuk besar/kasar diubah menjadi ukuran yang lebih kecil/halus. Proses grinding menggunakan mesin hammer mill.

Hammer mill merupakan mesin pengkonsumsi energi listrik terbesar kedua setelah mesin pellet, motor yang digunakan yaitu $250 \mathrm{~kW}$ pada satu mesin. Pengoperasian hammer mill berpengaruh signifikan terhadap tagihan listrik setiap bulan. [1]

Ukuran partikel (granulasi) hasil proses grinding akan mempengaruhi kemudahan pakan saat di press dalam roll and die pada mesin pellet. Penetrasi steam kedalam bahan baku akan maksimal sehingga pakan mudah di press dalam roll and die pada mesin pellet. Ada beberapa faktor yang mempengaruhi kapasitas dan granulasi hasil proses grinding diantaranya kualitas pisau/hammer, screen, blower dan feeder. Standar granulasi tiap bahan baku berbeda-beda tergantung untuk pembuatan pakan apa, tabel 1 merupakan standar granulasi bahan baku jagung, SBM (Soya Bean Meal) dan gandum.

Tabel 1. Standar granulasi bahan baku hasil grinding [2]

\begin{tabular}{ccc}
\hline Bahan baku & $\begin{array}{c}\text { Ukuran } \\
\text { partikel }\end{array}$ & Parameter \\
\hline Gandum & Halus & Minimal 80\% \\
\multirow{2}{*}{ Jagung } & Halus & Minimal 80\% \\
& Kasar & Minimal 80\% \\
SBM & Halus & Minimal 80\% \\
& Kasar & Minimal 60\% \\
\hline
\end{tabular}

Hammer mill adalah sebuah alat penggiling yang mempunyai rotor yang dapat berputar dan mempunyai alat pemecah berbentuk palu dimana palu-palu tersebut digantung pada suatu piringan. Hammer Mill menggunakan prinsip benturan/pukulan/impact dan juga dengan cara gesekan [3][4]. Hammer Mill di pasang menyatu pada sebuah batang/silinder putar yang berada di dalam ruangan berbentuk tabung dan di sekeliling dinding tabung. dipasang ayakan (screen). Produk hasil penumbukan akan keluar melalui lubang ayakan menuju ke lubang pengeluaran di bagian bawah tabung. Gambar 3 menunjukkan skema cara kerja mesin Hammer Mill.

Perkembangan mesin hammer mill semakin maju tiap tahunnya. Xuan pada tahun 2012 [5] mengembangkan alat ayakan terpisah pada mesin hammer mill. Produk tersebut diklaim dapat meningkatkan produktivitas dan menurunkan konsumsi energi terutama pada pengolahan bahan pada temperatur rendah. Pada tahun 2020 di Nigeria, Ojomo [6] mengembangkan mesin hammer mill dengan screen ayakan dobel. Kadar air pada bahan baku hasil dari mesin hammer mill tersebut dapat turun secara signifikan.

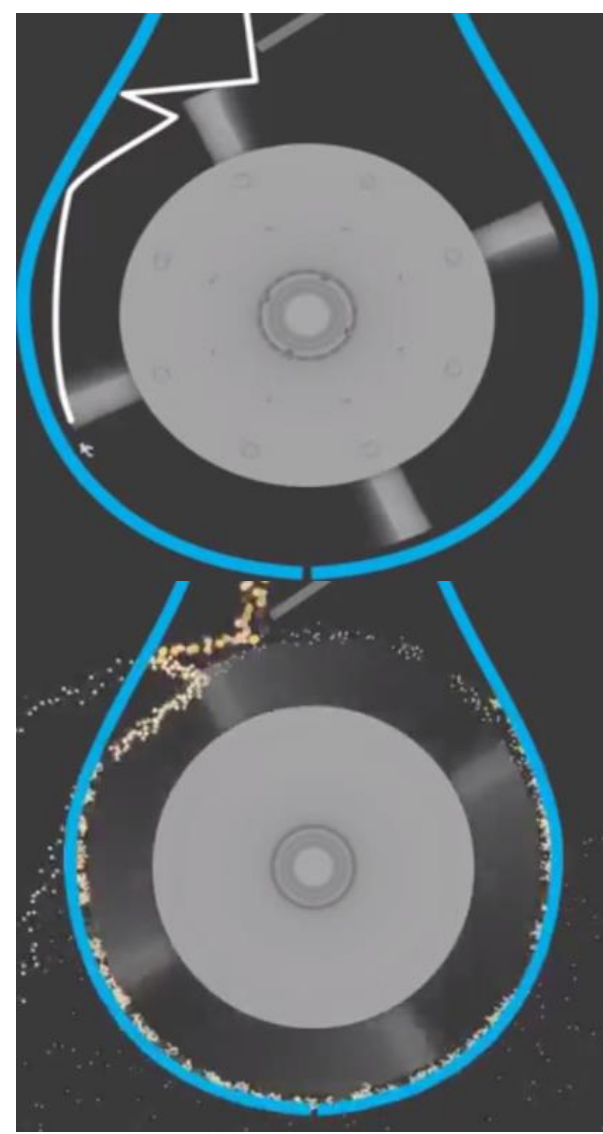

Gambar 1. Cara kerja mesin Hammer Mill [7][8]

Mesin ini cocok untuk bahan yang berupa curah. Hammer Mill tidak direkomendasikan untuk penggilingan halus atau bahan-bahan yang sangat keras tetapi dapat dipakai untuk bahanbahan yang berserat [9].

Screen berfungsi sebagai penyaring untuk memisahkan material yang sudah dihaluskan dan terletak pada bagian bawah Hammer Mill. Pada Hammer Mill bisa dipasang screen maksimal 4 unit, tetapi bisa juga divariasi dengan screen yang solid atau tidak ada lubang. Berikut merupakan screen yang terpasang pada Hammer Mill, terdapat frame untuk menahan screen agar rapat dengan dudukan. 

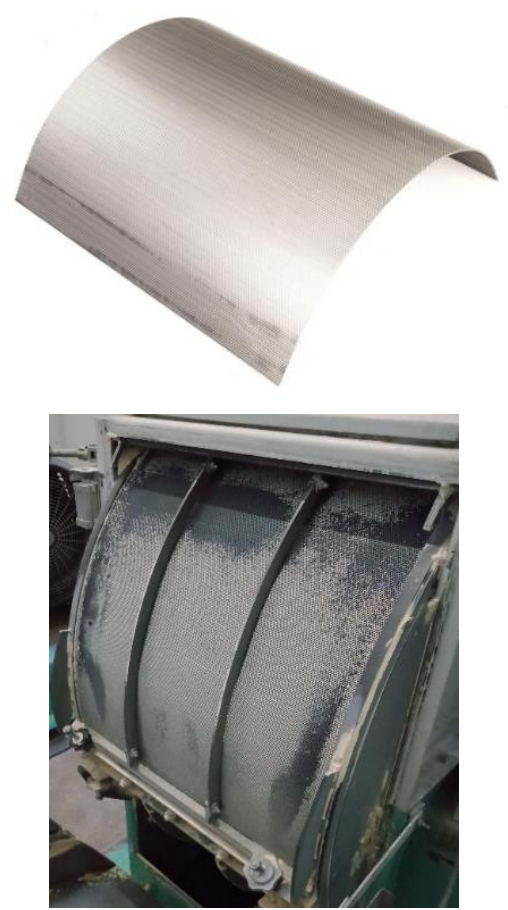

Gambar 2. Screen

Standar pemasangan screen pada hammer mill menurut Yancey [10] yaitu jarak antar lubang idealnya 1,5 kali diameter lubang, atau open area $30-40 \%$.

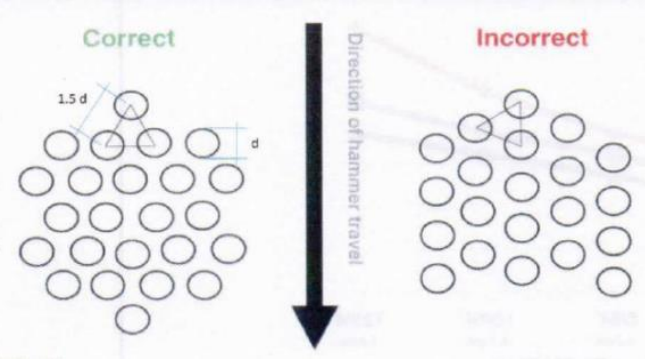

Gambar 3. Lubang Screen

Screen yang terpasang pada hammer mill yang ada di Plant Grobogan memiliki susunan antar lubang bersudut $60^{\circ}$. Open area screen yang disarankan sesuai dengan standar yaitu 30$40 \%$ atau jarak antar lubang 1,5 kali diameter lubang. Open area screen yang sesuai standar akan memaksimalkan kapasitas proses grinding. Jika spare part yang ada tidak sesuai dengan standar, maka cara memaksimalkan kapasitasnya yaitu dengan setting posisi screen. Open area adalah rasio yang mencerminkan berapa banyak lembaran yang ditempati lubang, biasanya dinyatakan dalam persen. Misalnya, jika luas lembaran berlubang $30 \%$, berarti $30 \%$ lembaran berlubang dan $70 \%$ lembaran adalah material. Menghitung open area screen dengan rumus seperti pada gambar berikut:

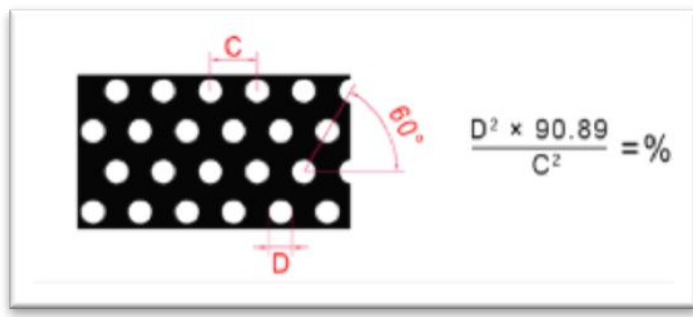

Gambar Error! No text of specified style

in document.. Rumus menghitung open area

screen

Open area $(\%)=\frac{\mathrm{D}^{2} \times 90,89}{\mathrm{C}^{2}}$

Keterangan :

$\mathrm{D}$ : diameter lubang screen $(\mathrm{mm})$

$\mathrm{C}$ : jarak antar lubang screen $(\mathrm{mm})$

Blower berfungsi menghisap udara untuk mempercepat proses turunnya bahan baku ke grinding chamber. Parameter blower yang berpengaruh pada proses grinding yaitu bukaan damper atau valve pada pipa saluran udara. Udara masuk bisa disetting $100 \%$ kapasitas blower, akan tetapi jika di setting $100 \%$ dikhawatirkan heavy particle akan terbawa masuk kedalam grinding chamber. Terdapat 5 lubang indikator jumlah udara masuk. Setting damper blower masih manual dengan menaikkan atau menurunkan tuas damper. Berikut merupakan setting damper blower.

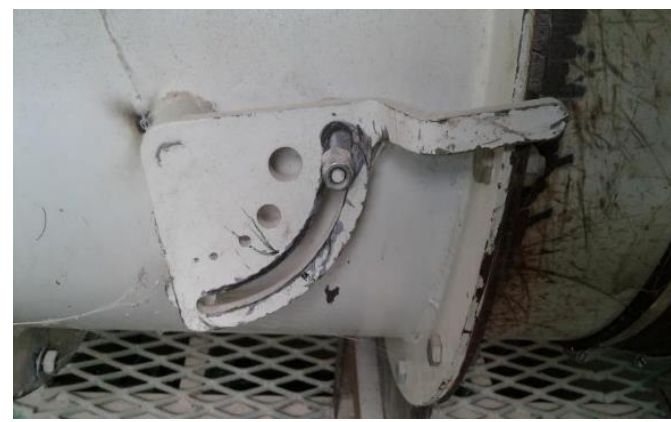

Gambar 4. Blower

\section{Metodologi Penelitian}

Bahan baku yang digunakan yaitu jagung lokal yang telah dikeringkan dan ditambahkan antimold. Bahan baku telah ditampung terlebih dahulu di silo agar mudah dalam proses feeder mesin hammer mill.

Alat yang digunakan :

1. Mesin Hammer mill Buhler

AHZC-67047-1-EN-1107

2. Software Wincos

3. Ayakan (mesh)

4. Timbangan digital
5. Stopwach

6. Kalkulator

7. Kunci ring 
Beberapa parameter yang perlu di setting yaitu:

\section{a. Setting posisi screen}

Screen yang digunakan pada penelitian adalah 2,5 dan $3 \mathrm{~mm}$. Nilai open area screen bervariasi yaitu 35,4\%, 40,3\%dan 51\%. Posisi screen yang terpasang sangat berpengaruh terhadap kapasitas mesin hammer mill dan outputnya yaitu kehalusan (granulasi) material.

\section{b. Setting feeder (DFCO)}

Setting DFCO yang diterapkan saat trial yaitu $90 \%$.

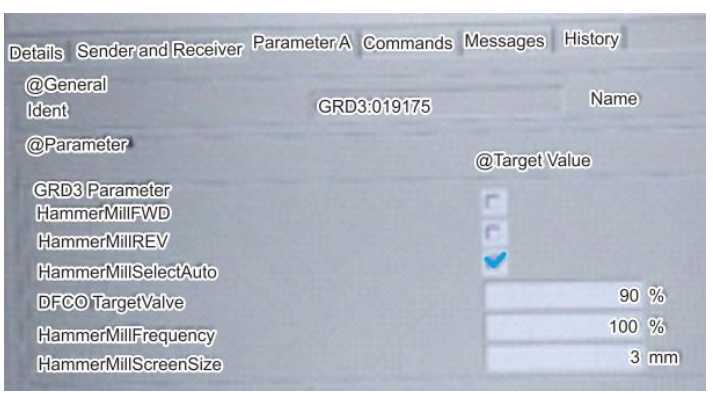

Gambar 5. Setting DFCO

\section{c. Setting blower}

Setting blower yang diterapkan saat penelitian yaitu bukaan 2,5; 3 dan 3,5.

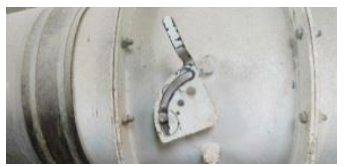

(a)

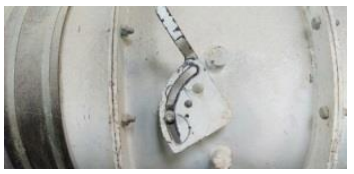

(b)

Gambar 6. Setting Blower :(a) 2,5 (b) 3 (c) 3,5

d. Cek kebersihan aspiration filter

Parameter yang harus dijaga selama proses penelitian dan juga saat proses operasional berlangsung yaitu kebersihan aspiration filter. Jika filter tersumbat atau kotor, sirkulasi udara akan terhambat sehingga kapasitas dan granulasi tidak tercapai. Filter harus dibersihkan tepat waktu sesuai dengan jadwal pembersihan.

e. Penelitian kapasitas

Penelitian kapasitas hammer mill dilakukan dengan menerapkan parameter setting posisi screen, DFCO, dan blower tertentu. Selain menghitung kapasitas juga mengecek apakah granulasi sudah sesuai dengan standar, kemudian dianalisa pengaruh parameter tersebut terhadap kapasitas dan granulasi bahan baku hasil proses grinding.

a. Kapasitas

Menghitung kapasitas berdasarkan pada berat bahan baku dan waktu proses grinding, dengan rumus yaitu,

Kapasitas $=\frac{\text { Berat bahan baku (ton) }}{\text { Waktu proses grinding (jam) }}$

Menghitung granulasi tergantung partikel yang diinginkan, grinding halus atau kasar.

b. Grinding kasar

Sampel hasil grinding diayak dengan ayakan mesh 18 kemudian partikel kasar ditimbang dan dibandingkan dengan total berat sampel, rumus yang digunakan yaitu, Grinding kasar $=\frac{\text { Berat partikel kasar }(\text { gram })}{\text { Berat total sampel }(\text { gram })} \times 100 \%$

c. Grinding halus

Sampel hasil grinding diayak dengan ayakan mesh 18 kemudian partikel halus ditimbang dan dibandingkan dengan total berat sampel, rumus yang digunakan yaitu,

$$
\begin{aligned}
& \text { Grinding halus } \\
& =\frac{\text { Berat partikel halus }(\text { gram })}{\text { Berat total sampel }} \times 100 \%
\end{aligned}
$$

\section{Hasil dan Pembahasan}

Nilai open area screen yang terpasang pada hammer mill ditampilkan pada tabel 2. Dari tabel 2 diperoleh nilai open area screen tertinggi pada kondisi III kemudian kondisi I dan paling rendah pada kondisi II. Pada kondisi III sebesar 51,13\% lembaran screen berlubang.

Tabel 2. Nilai Open Area Screen

\begin{tabular}{cccc}
\hline $\begin{array}{c}\text { Kondisi } \\
\text { setting }\end{array}$ & $\begin{array}{c}\text { Diameter } \\
(\mathbf{m m})\end{array}$ & $\begin{array}{c}\text { Jarak } \\
\text { lubang } \\
(\mathbf{m m})\end{array}$ & $\begin{array}{c}\text { Open } \\
\text { area } \\
(\boldsymbol{\%})\end{array}$ \\
\hline I & 2,5 & 3,75 & 40,4 \\
II & 2,5 & 4 & 35,5 \\
III & 3 & 4 & 51,13 \\
\hline
\end{tabular}

Penelitian dilakukan dengan tiga kondisi setting meliputi bukaan blower, open area screen, DFCO (setting feeder) dan kondisi hammer. Berikut ditampilkan pada tabel 3. 


\section{Tabel 3. Setting Posisi Screen dan Blower}

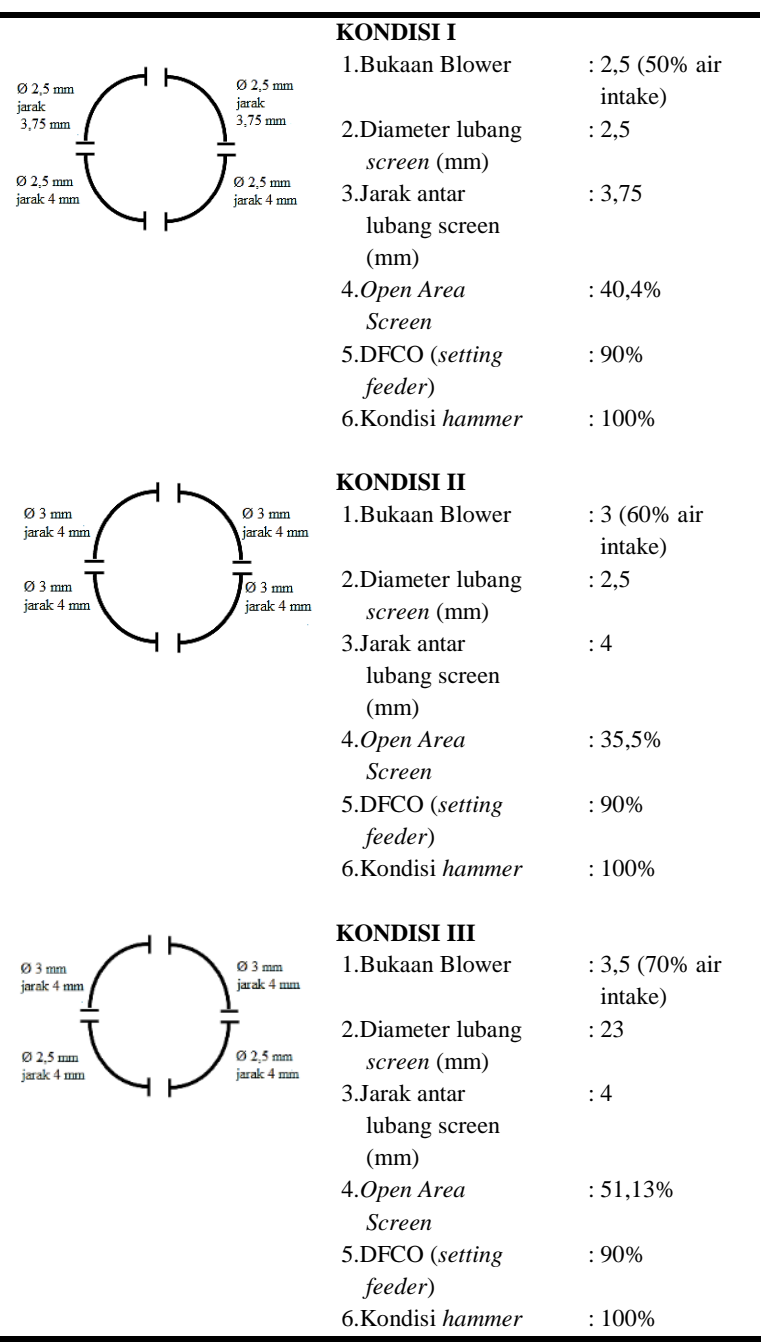

Dari hasil penelitian diperoleh kapasitas pada kondisi pertama (trial pertama) lebih rendah dibanding trial kedua dan ketiga. Akan tetapi prosentase granulasi lebih terjadi karena menggunakan screen $2,5 \mathrm{~mm}$ dan setting blower kurang besar. Trial kedua memiliki kapasitas tinggi tetapi granulasi rendah dibandingkan trial pertama dan ketiga karena menggunakan screen $3 \mathrm{~mm}$. Trial ketiga kapasitas lebih tinggi dibanding trial pertama dan granulasi lebih baik dibandingkan dengan trial kedua karena menggunakan kombinasi screen berdiameter 2,5 $\mathrm{mm}$ dan $3 \mathrm{~mm}$ serta setting blower besar ditampilkan pada gambar 7. Screen diameter 2,5 $\mathrm{mm}$ akan menghasilkan granulasi yang lebih baik dibandingkan dengan screen yang berdiameter $3 \mathrm{~mm}$, tetapi kapasitas yang dihasilkan lebih rendah. Screen berdiameter 3 mm akan menghasilkan kapasitas yang lebih tinggi dibandingkan dengan screen berdiameter $2,5 \mathrm{~mm}$, tetapi granulasi yang dihasilkan kurang baik. Dari hasil penelitian, trial yang ketiga merupakan yang paling baik karena setelah dihitung kapasitas hanya selisih $174 \mathrm{~kg}$ dari trial kedua, selain meningkatkan kapasitas tetapi tetap menjaga granulasi hasil proses grinding.

Pada gambar 8. ditampilkan hubungan antara open area screen dengan arus. Pada kondisi III, arus yang digunakan oleh mesin hammer mill sebesar 420 A dengan tetap menjaga kapasitas sebesar 20, $85 \mathrm{MT} / \mathrm{h}$ serta granulasi yang dihasilkan sebesar $85 \%$. Kondisi III merupakan kondisi paling baik yang diperoleh dari ketiga trial. Dimana optimasi dilakukan untuk memaksimalkan penggunaan mesin hammer mill yang merupakan mesin pengonsumsi energi listrik terbesar kedua setelah mesin pellet pada suatu plant. Kombinasi posisi screen diameter 2,5 $\mathrm{mm}$ dan $3 \mathrm{~mm}$ akan menghasilkan kapasitas serta granulasi yang baik jika spesifikasi screen sudah sesuai dengan standar yang disarankan.

Penggunaan ukuran diameter screen berpengaruh konsumsi energi (ditunjukkan dengan arus) yang dipakai oleh mesin hammermill. Menurut Mani, ukuran diameter screen berpengaruh pada konsumsi energi. Hal ini dibuktikan dengan penelitian konsumsi energi mesin hammermill dengan bahan baku gandum [11]. Sejalan dengan itu, penelitian Mugabi menunjukkan konsumsi energi pada mesin hammermill semakin tinggi dengan pemakaian ukuran diameter screen lebih kecil. Dimana Mugabi meneliti ukuran screen diameter 1,5; 2; dan $3 \mathrm{~mm}$ dengan bahan baku biji jagung [12]. Selanjutnya Ibrahim meniliti bahan baku jagung dengan ukuran screen diameter 2, 4, dan $6 \mathrm{~mm}$ menunjukkan konsumsi energi terendah pada ukuran screen $6 \mathrm{~mm}$ [13].

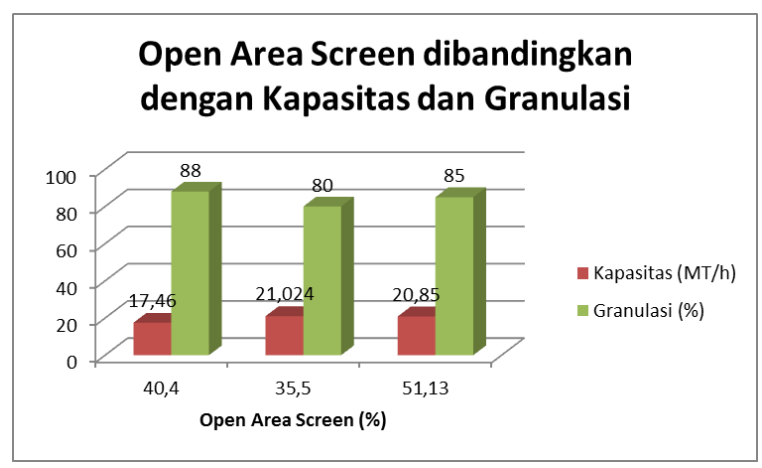

Gambar 7. Open Area Screen dibanding Kapasitas dan Granulasi 


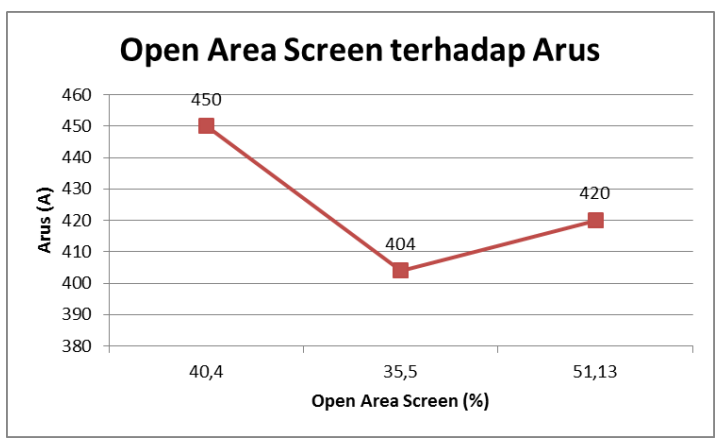

Gambar 8. Perbandingan Open Area Screen dengan Arus

\section{Penutup}

Berdasarkan hasil trial dan analisis pada proses grinding, dapat ditarik kesimpulan yaitu Penggunaan screen diameter 2,5 $\mathrm{mm}$ dan $3 \mathrm{~mm}$, serta setting posisi screen $3 \mathrm{~mm}$ di bagian atas dan 2,5 $\mathrm{mm}$ di bagian bawah menghasilkan kapasitas dan granulasi yang lebih baik dibandingkan penggunaan screen hanya diameter 2,5 dan $3 \mathrm{~mm}$.

Setting blower dan DFCO saling mempengaruhi. Semakin besar setting blower dan DFCO, semakin besar pula kapasitas proses grinding, tetapi arus motor selama proses grinding tinggi. Semakin besar bukaan blower akan menyebabkan non material seperti batu dan logam akan ikut masuk ke dalam chamber grinding karena hisapan angin yang tinggi.

\section{Daftar Pustaka}

[1] D. MI, B. A, E. H. Z, and A. S, "Grinding Parameters and their Effects on the Quality of Corn for Feed Processing," J. Food Process. Technol., vol. 06, no. 09, 2015.

[2] A. A. Rubio, J. B. Hess, W. D. Berry, W. A. Dozier, and W. J. Pacheco, "Effects of corn particle size on broiler performance during the starter, grower, and finisher periods," J. Appl. Poult. Res., vol. 29, no. 2, pp. 352-361, 2020.

[3] V. Kosse and J. Mathew, "Design of hammer mills for optimum performancee," in Proceeding of the Institution of Mechanical Engineers, 2001, pp. 87-94.
[4] F. Shi, T. Kojovic, and J. S. Esterle, "An EnergyBased Model for Swing Hammer Mills," Int. J. Miner. Process., vol. 71, pp. 147-166, 2003.

[5] C. Xuan, L. Cao, P. Wu, Y. Ma, and D. Han, "Development on a Hammer Mill with Separate Sieving Device," TELKOMNIKA Indones. J. Electr. Eng., vol. 10, no. 6, pp. 1381-1386, 2012.

[6] O. A. Ojomo and A. J. Fawohunre, "Development of a Hammer Mill with Double Sieving Screens," Eur. J. Eng. Res. Sci., vol. 5, no. 5, pp. 617-621, 2020.

[7] R. Cretan and P. W. Matthews, "Popular responses to city-text changes : street naming and the politics of practicality in a post-socialist martyr city," Area, vol. 48, no. 1, pp. 92-102, 2016.

[8] Tim, Operating Instructions Hammer Mill AHZC67048-1-en-1107 Buhler. Changzhou: Changzou Machinery CO. LTD., 2014.

[9] T. H. Mohamed, H. A. Radwan, A. O. Elashhab, and M. Y. Adly, "Design and evaluate of a small hammer mill," J. Agric. Res., vol. 5, no. Agustus, pp. 481-496, 2015.

[10] N. Yancey, C. T. Wright, and T. L. Westover, "Optimizing Hammer Mill Performance Through Screen Selection and Hammer Design," Biofuels, vol. 4, no. 1, pp. 85-94, 2013.

[11] S. Mani, L. G. Tabil, S. Sokhansanj, and H. R. Chicago, "Grinding Performance and Physical Properties of Selected Biomass Grinding Performance and Physical Properties of Selected Biomass," vol. 0300, no. xx.

[12] R. Mugabi, Y. B. Byaruhanga, K. M. Eskridge, and C. L. Weller, "Performance evaluation of a hammer mill during grinding of maize grains," Agric. Eng. Int. CIGR J., vol. 21, no. 2, pp. 170179, 2019.

[13] M. Ibrahim, M. Omran, and E. Abd EL-Rhman, "Design and Evaluation of Crushing Hammer Mill," Misr J. Agric. Eng., vol. 36, no. 1, pp. 124, 2019. 